\title{
Psicologia, Psicanálise, Arte e EnCarceramento JuVenil
}

\author{
Marlise Eugenie D'lcarahy1 \\ Rita Maria Manso de Barros2 \\ Lucia Maria de Freitas Perez3 \\ Andréa Martello4
}

\section{RESUMO}

A experiência de encarceramento precoce, frequentemente agravada por violências impetradas, desde o momento da apreensão, tanto por agentes do Estado quanto por anônimos transeuntes e estendida ao interior de instituições públicas, é relatada por inúmeros adolescentes que cumprem medida socioeducativa em meio fechado no Rio de Janeiro. As estatísticas dessa macabra violência permanecem subestimadas. Neste perverso cenário instituído, como a Psicologia, a Psicanálise e a Arte podem contribuir para a elaboração subjetiva dos socioeducandos que vivenciaram tão poderosos traumas, bem como para a transformação de tão cruel status quo?

PalavRas-Chaves: Socioeducação, adolescência, violência, instituições públicas, Psicanálise, Arte.

\footnotetext{
1 Psicanalista. Psicóloga do Tribunal de Justiça do Rio de Janeiro. Membro associado do Corpo Freudiano Escola de Psicanálise do Rio de Janeiro. E-mail: marliseugenie@gmail.com

2 Psicanalista. Professora Titular do DFE/UNIRIO - Universidade Federal do Estado do Rio de Janeiro. Professora do Programa de Pós-Graduação em Psicanálise da UERJ. E-mail: ritamanso2008@gmail.com

3 Psicanalista. Professora Adjunta 4 do DFE/UNIRIO - Universidade Federal do Estado do Rio de Janeiro. Membro do Corpo Freudiano Escola de Psicanálise do Rio de Janeiro. E-mail: luciafreitasperez@gmail.com

${ }_{4}$ Psicanalista. Professora Adjunta 2 do DFE/UNIRIO - Universidade Federal do Estado do Rio de Janeiro. E-mail: deamartello@gmail.com
} 
A experiência de encarceramento precoce, frequentemente agravada por violências impetradas, desde o momento da apreensão, tanto por agentes do Estado quanto por anônimos transeuntes e estendida ao interior de instituições públicas, é relatada por inúmeros adolescentes que cumprem medida socioeducativa em meio fechado no Rio de Janeiro. As estatísticas dessa macabra violência permanecem subestimadas. Neste perverso cenário instituído, como a Psicologia, a Psicanálise e a Arte podem contribuir para a elaboração subjetiva dos socioeducandos que vivenciaram tão poderosos traumas, bem como para a transformação de tão cruel status quo?

Enquanto psicanalistas, professoras da Escola de Educação da Universidade Federal do Estado do Rio Janeiro, responsáveis pela condução do Programa de Extensão Enredando Saberes: impasses da prática (PROEX/UNIRIO), e psicóloga responsável pelo Serviço de Psicologia da Vara de Execuções de Medidas Socioeducativas e pelo Programa Eu Apoio a Voz do Adolescente, firmamos o desafio de pensar sobre essa questão que nos é cotidianamente colocada.

O Estatuto da Criança e do Adolescente, próximo de completar 30 anos, prevê que, ao adolescente de doze a dezoito anos a quem seja imputada a prática de ato infracional, poderá ser imposta medida socioeducativa, cujo objetivo difere das penas aplicadas aos adultos. A diferença se sustenta no conceito de adolescente adotado pelo legislador como pessoa em desenvolvimento. Se para os adultos a pena significa uma punição por um crime ou contravenção cometidos, as medidas socioeducativas têm duplo objetivo: contribuir para que o adolescente se responsabilize pelo ato praticado, como também que Ihe seja oferecida a oportunidade de refletir e de se transformar, tal como pessoa em desenvolvimento, que é.

Infelizmente, no campo prático, o Estatuto da Criança e do Adolescente é cumprido apenas parcialmente quando à temática é Socioeducação. O primeiro impasse que se observa é precariedade da rede de equipamentos dos municípios, responsáveis legais pelo cumprimento das medidas socioeducativas em meio aberto. Os profissionais dos Centros de Referência Especializados de Assistência Social CREASs-, além de serem responsáveis pelo acompanhamento de jovens em conflito com a lei, também têm atribuição de cuidar de casos de envolvendo violência 
doméstica, vulnerabilidade familiar, direitos de idosos e inúmeras situações em que haja risco de violação de direitos.

Em razão da sobrecarga de trabalho, do número reduzido de funcionários nos CREASs e do funcionamento deficitário dos serviços dos municípios; parte do sistema Judiciário parece não reconhecer a eficácia das ações socioeducativas em meio aberto, e optar pela aplicação de alto índice de internações em meio fechado. As medidas de restrição de liberdade, apesar de bastante aplicadas, são previstas como excepcionais e utilizáveis somente depois de esgotadas todas as demais alternativas.

Enquanto relatos persistentes de violação de direitos constitucionais contra adolescentes pobres a quem são imputados prática de atos infracionais são denunciados cotidianamente, grande parte dos meios de comunicação de massa insiste em alastrar a ideia de que os adolescentes que praticam ato infracional grave permanecem impunes em razão do Estatuto da Criança e do Adolescente - Lei 8.069 de 1990. Ao contrário do que irresponsavelmente se apregoa; a quantidade de socioeducandos que vivenciou a experiência de encarceramento é altíssima.

$X$, jovem forte e negro de dezesseis anos, residente em uma das favelas do Rio de Janeiro, chega ao Serviço de Psicologia da VEMSE. Extremamente abalado, escondendo os olhos marejados sob o boné, esforça-se para responder a pergunta da psicóloga sobre sua auto avaliação e experiência na internação. Sua mãe relata que o jovem não consegue mais sair de casa desacompanhado, devido ao trauma vivenciado e sobre o qual ainda tem medo de falar. $X$ foi um dos adolescentes que cumpria medida socioeducativa de internação nas unidades do DEGASE e que foi beneficiado pela decisão do STF, que atendendo ao pedido de Habeas Corpus (HC) de número 143988 da Defensoria Pública do Espirito Santo, determinou a extensão do remédio constitucional às unidades de internação socioeducativas nos Estados do Rio de Janeiro, da Bahia, do Ceará e de Pernambuco. Na decisão, o Ministro Fachin delimitou a superlotação das unidades de internação, estabelecendo em 119\% a taxa de ocupação permitida nestas unidades.

Para atender a determinação do Ministro, a juíza titular da VEMSE Dra. Lúcia Glioche passou a prolatar decisão de cumprimento de medida socioeducativa de internação domiciliar para parte dos jovens que estavam internados nas unidades do Departamento Geral de Ações Sócio Educativas - DEGASE, órgão do Governo do 
Estado do Rio de Janeiro. Diferentemente das demais medidas socioeducativas previstas no Estatuto da Criança e do Adolescente que determinam quais os departamentos e órgãos que devem executá-las e redigir os relatórios individuais dos adolescentes, a internação domiciliar, ainda não disciplinada por lei, deixava incerto que órgão acompanharia a execução do remédio e produziria os relatórios individuais. Diante deste impasse, a magistrada consultou as equipes técnicas da Vara de Execuções de Medidas Socioeducativas da Comarca do Rio de Janeiro, que aceitaram por ora o desafio de acompanhar os adolescentes e de elaborar os respectivos documentos que permitissem as reavaliações judiciais.

Como X, muitos socioeducandos recém liberados de unidades de internação, cujas famílias estão desempregadas e enfrentam extrema dificuldade financeira para custear o transporte, só conseguem comparecer aos agendamentos nas equipes técnicas do juízo, se acompanhados. Estão extremamente fragilizados e têm pânico de voltarem a sofrer o que vivenciaram. A sala do serviço de Psicologia da Vara de Execução situa-se no prédio do Centro Cultural da Justiça, próximo à Assembleia Legislativa e ao Museu Histórico Nacional, cujos setores educativos e departamento de Cultura desenvolvem atividades de acolhimento preparatórias e posteriores aos atendimentos individuais. As atividades desenvolvidas por esses três parceiros institucionais integram o Programa Eu Apoio A voz do Adolescente, proposta pelo serviço de psicologia da VEMSE, que conta ainda com o convênio entre o Tribunal de Justiça/UNIRIO, através do Programa de Extensão Enredando saberes: impasses da prática (PROEX-UNIRIO) que incluem os Projetos de Extensão Em nome do sujeito: encontros de Psicanálise, Educação, Literatura e Artes da Escola de Educação e $O$ leitor como protagonista proveniente da Escola de Teatro. Eu Apoio A voz do Adolescente tem também a participação do Projeto Parlamento Juvenil da ALERJ. Esse conjunto de parceiros institucionais com seus profissionais engajados na causa da Socioeducação se juntam ao serviço de Psicologia da VEMSE oferecendo espaços de escuta e de elaboração de questões extremamente complexas, que extrapolam a simples avaliação do adolescente frente ao ato infracional a que responde, acolhendoo como pessoa em desenvolvimento. Por essa razão, avaliar, mas também auxiliar o adolescente a encontrar melhores soluções para os problemas que contribuíram para a prática do ato infracional encontra-se no escopo da intervenção que o Serviço de 
Psicologia do juízo se propõe e que se traduz no documento técnico incorporado aos autos, e que subsidia a decisão da magistrada.

Por outro lado, o reposicionamento subjetivo que convoque o adolescente a agir de acordo com a lei tem relação direta com o fato de o Estado cumprir suas obrigações legais, garantindo a construção de uma robusta rede que oferte de Educação, oportunidade de trabalho, moradia, Cultura, Segurança e transporte. Sem essa rede civilizatória, os filhos da população mais pobre permanecem largados a própria sorte.

\section{Sobre Os Jovens E A LeI, Onde As Oportunidades Não São lguais Para TODOS}

Como promover efeitos educacionais em jovens que cumprem processos judiciais por conflito com a lei, em um contexto de divisão social radical, em classes econômicas, cujas barreiras, ainda que invisíveis e escondidas, são impostas cotidiana e violentamente nesses mesmos jovens? Enquanto psicanalistas, permanecermos no campo da subjetividade e da perícia psiquicamente patológica, mas ouvimos histórias de realidade objetiva que se revelam extremamente devastadoras, fazendo com que o acesso à cidadania, ao patrimônio cultural e democrático estejam muito além do alcance da maioria desses jovens.

Do lugar de psicanalistas e professoras universitárias inseridas na polis, visamos com nossas pesquisas ainda em andamento, decorrentes das ações extensivas dos já citados programa e projetos de extensão, um mais além da técnica, a ética, que para nós psicanalistas é sempre ética do desejo. Na perspectiva que assumimos, não é mais possível tomar a psicanálise como apolítica e o psicanalista como indiferente no trato das questões sociais. No pensamento de Freud (1921/1976c), a psicologia individual é também social, desde os primórdios da vivência edípica. Para Lacan, o inconsciente é a política, o que, em nosso entendimento, destaca o quanto somos influenciados, determinados e até manipulados pelo discurso do Outro. 


\section{Por Uma Sociedade Mais Justa}

Importante deixar claro que as atividades da Justiça infracional na Comarca do Rio de Janeiro estão divididas em duas varas: a VIJ - Vara da Infância e Juventude do Rio de Janeiro, que decide pela aplicação da primeira medida socioeducativa de todos os processos de Conhecimento e a VEMSE - Vara de Execuções de Medidas Socioeducativas da Comarca do Rio de Janeiro, responsável por fiscalizar a execução de todas as medidas socioeducativas. Quando um adolescente responde a processo infracional e recebe determinação judicial para que cumpra determinada medida socioeducativa, seu processo é extinto na Vara da Infância e da Juventude - VIJ - e um novo número é gerado, desta vez na Vara de Execuções de Medidas Socioeducativas do Rio de janeiro, que irá executá-la até a sua extinção. A VEMSE passou a dispor de um Serviço de Psicologia em Junho de 2017, a partir da lotação da psicóloga e psicanalista Marlise E. D'lcarahy, co-autora desse artigo, que, atendendo à demanda da magistrada Lúcia Glioche, propôs a criação do Programa Eu Apoio e as primeiras estratégias do trabalho para adolescentes em cumprimento de medidas socioeducativas de Liberdade Assistida, convidando os já citados Programa e Projeto de Extensão da UNIRIO para uma parceria.

Outros primeiros parceiros do Programa Eu Apoio foram o Museu Histórico Nacional - MHN, o Centro Cultural Museu da Justiça - CCMJ e a Assembleia Legislativa do Rio de Janeiro - ALERJ, através do Projeto Parlamento Juvenil na ALERJ e dos setores educativos das três instituições. Isso nos permitiu oferecer a todos os adolescentes em cumprimento dessa medida três experiências culturais, mediadas por educadores, historiadores, professores e alunos dos cursos de pedagogia, música, medicina e biologia da UNIRIO, para citar alguns.

Cada visita é mediada pelo setor educativo das instituições parceiras (MHN, CCMJ e ALERJ), onde são abordados temas como os aspectos históricos da formação do povo brasileiro, democracia, justiça, leis, esfera pública, direitos, após a qual, os jovens e todos que acompanham a visita, incluindo familiares dos jovens, os profissionais da secretaria de assistência social (CREAS) são convidados pela psicóloga da VEMSE e pelas professoras da UNIRIO para uma conversação sobre as questões suscitadas nas visitas. Trata-se de uma convocação para que os 
adolescentes se manifestem em suas singularidades de sujeitos sobre suas interrogações acerca dos desafios de Cidadania que considerem mais relevantes.

Logo após os quatro primeiros meses de funcionamento do Programa Eu Apoio pudemos constatar que a maioria de adolescentes atendidos também cumpriu medida socioeducativa mais gravosa, de internação provisória ou definitiva, em meio fechado, onde, não raro, ouvíamos de diferentes jovens relatos semelhantes de tratamento extremamente violento e punitivo dispensado a eles pelas autoridades policiais e nas unidades socioeducativas de meio fechado.

Que destino ético dar a tão dramático dado? Apresentamo-lo às autoridades judiciais e à comunidade acadêmica, para que, congraçados, enfrentemos tão grande desafio. Ainda que somente dentro dos escopos de nossas funções institucionais, compartilhamos a alegria de contribuir para que nossas e outras instituições da rede de atenção ao socioeducando possam ouvir o público jurisdicionado, relativamente à eficácia da intervenção do Poder Judiciário e do Poder Executivo em suas vidas. $O$ acesso a esses dados é importante para a melhoria da prestação jurisdicional e a pacificação responsável dos conflitos sociais.

O recorte social dos adolescentes que respondem a processo infracional corresponde à mesma camada social de excluídos em relação às políticas públicas civilizatórias, de saúde, escola, transporte, segurança, arte etc. Ou seja, os jurisdicionados a quem se atribui autoria nas varas infracionais do Rio de Janeiro são oriundos das camadas mais pauperizadas da sociedade, com baixa escolaridade, pouca inserção no mercado de trabalho, muitos sofrem pressão familiar e social para que "banquem" seu sustento e de familiares.

Loic Waquant, em As prisões da miséria (2011), defende a tese que quanto menos o Estado investir em políticas públicas sociais de redistribuição de renda; mais policial e penitenciário ele o será. Isso porque a opção por um Estado menor "é a própria causa da escalada generalizada da insegurança objetiva e subjetiva" (WACQUANT, 2011, p. 9). O autor argumenta que a política de Segurança Pública, cujo slogan é "tolerância zero" é responsável pelo crescente número de pessoas presas, cujo ponto máximo é o encarceramento sistemático da juventude pobre. Observa que tal modelo surgiu nos anos 90 em Nova York, sendo, em seguida, exportado para a Europa e para a América Latina. Acresce que o ostensivo discurso 
das mídias oficiais "naturaliza a ideia de: delinquência dos jovens, violência urbana [...] cujos centros de irradiação seriam bairros sensíveis às incivilidades" (WACQUANT, 2011, p. 25). A propagação dessas noções "outorgam-Ihes a dignidade de fatos sociais ou mesmo de categorias de análise" (WACQUANT, 2011, p. 25). Wacquant pondera que, na verdade, a insegurança decorre da má distribuição de renda e da manutenção de classes sociais distintas, situações consideradas naturais pelo Estado neoliberal, cuja população mais desfavorecida, sofre duplamente, por ser aquela cujos filhos estão mais propensos a cair nas redes da ilegalidade para sobreviver.

\footnotetext{
$\mathrm{Na}$ ausência de qualquer rede de proteção, é certo que a juventude dos bairros populares pelo peso do desemprego e subemprego crônicos continuará a buscar no capitalismo de pilhagem de rua [...] os meios de sobreviver e realizar os valores do código de honra masculino, já que não consegue escapar da miséria no cotidiano (WACQUANT, 2011, p.10).
}

A especificidade do período turbulento de travessia da adolescência apontado na Constituição Federal (1998), e nas leis daí decorrentes, no Estatuto da Criança e do adolescente - Lei 8060 (1990) e no SINASE (2006), já fora demarcada pelo criador da Psicanálise. Em Romances familiares (1909 [1908]/1996), Freud ensina que a rebeldia juvenil eclode de modo geral sob intensa batalha subjetiva e que o trabalho psíquico de desligamento da autoridade daqueles que foram fonte de amor é certamente um dos mais difíceis, caracterizando a dolorosa passagem da infância para a vida adulta.

Ao crescer, o indivíduo liberta-se da autoridade dos pais, o que constitui um dos mais necessários, ainda que mais dolorosos, resultados do curso de seu desenvolvimento. Tal liberação é primordial e presume-se que todos os que atingiram a normalidade lograram-na pelo menos em parte. Na verdade, todo o progresso da sociedade repousa sobre a oposição entre as gerações sucessivas (FREUD, 1909 [1908] / 1976d, p. 219).

Os efeitos salutares da rebeldia juvenil não se limitam à conquista de relativa autonomia subjetiva em relação aos valores daqueles que foram as pessoas mais importantes na infância; também do ponto de vista social, a rebeldia juvenil exerce significativa função histórica. A insurreição social que conduziu à derrubada da Monarquia e instauração da República, na Revolução Francesa, de 1789, contou com a participação de adolescentes. Também a história do México presta homenagem à 
resistência de seis adolescentes, entre 13 e 19 anos, que se aquartelaram no Castelo de Chapultepec, em 1847, defendendo até à morte seu território natal, contra as investidas estadunidenses.

Evidentemente, que não se pretende com esses dados desresponsabilizar o adolescente que responde a processo infracional pelas consequências de seus atos; mas de, como representantes de discurso institucional, interrogar se a forma como temos lidado com os atos de rebeldia juvenil tem contribuído para a transformação das causas econômicas e políticas que influem nas escolhas individuais desses jovens. Terá o estado conservado unicamente sua dimensão punitiva ao resolver os conflitos sociais envolvendo adolescentes? Poder-se-ia colocar em prática estratégias que busquem provocar efeitos transformadores dos jovens e do tecido social?

Nesse contexto, ouvir os adolescentes, convidando-os a se expressarem sobre o que deveria ser transformado é trabalho socioeducativo crucial. O convite é para que além de se manifestarem oralmente, possam também anexar essas considerações aos processos, através de documento denominado $A$ Voz do Adolescente, fazendo ecoar a potente e subversiva voz de nossa juventude, uma voz que talvez possa despertar nossa justiça - reconhecidamente cega, mas não necessariamente surda.

Vem em nosso apoio a obra do filósofo Anzel Honneth (2003), que ao tomar o amor como primeira condição para a constituição subjetiva e ao utilizar as noções de reconhecimento e desrespeito, detecta uma continuidade entre os campos afetivo, social, jurídico e político. Em sua perspectiva, o motor das lutas políticas não é o interesse econômico ou a luta pela sobrevivência, e sim, o sentimento de injustiça que provém de experiências nas quais o reconhecimento é recusado. Sentimento de injustiça que ficaria ancorado nas memórias afetivas, funcionando como impulsionadores de conflitos sociais.

Encontramos também afinidades com as ideias de Judith Butler, que, especialmente, em Vida precária (2004), não articula o reconhecimento à identidade, nem situa o problema das questões sociais na redistribuição mais justa de recursos, mas propõe uma nova forma de politização cujo fundamento não mais reside no pai ou no Estado, e sim, na vulnerabilidade. A filósofa propõe que o deslocamento das formas tradicionais do poder e da política e o reconhecimento de que somos todos 
vulneráveis poderia produzir uma transformação na relação entre grupos, povos e culturas (BUTLER, 2004, p. 67).

A vulnerabilidade pode ser entendida como tendo uma proximidade com o conceito de castração para nós, psicanalistas. Na fórmula da sexuação proposta por Lacan (1964/1985b), o lado feminino dá lugar ao pensamento de que há sujeitos nãotodos seduzidos pela dimensão fálica. Para àqueles que se agarram desesperadamente ao lado masculino, não castrado, imaginariamente completo, narcisicamente embotado, o lado feminino, presente em todos os sujeitos castrados, remete ao horror. Não à toa, passam a aspirar ao extermínio do outro na paixão do ódio.

Ao invés da vitimização, o reconhecimento da vulnerabilidade possibilita à potência, concebendo uma ética e uma estética que consideramos mais próxima do feminino por enfrentar de frente a questão da castração, que rege a lógica masculina, cujas respostas operam como um véu em relação à castração.

Embora acreditemos na Socioeducação, sabemos das dificuldades que cercam o exercício da convocação do sujeito em psicanálise e na sociedade. Fazer operar a função do sujeito difere de um adestramento comportamental. Não há um Ideal a guiar o pensamento, o pensamento não está a serviço de uma moral. Dado que não se trata de uma transmissão de valores e sim da criação de um ambiente transferencial, que permita o questionamento.

Também nos voltamos para o trabalho dos técnicos, alunos e profissionais envolvidos nestas atividades socioeducativas, tanto de Liberdade Assistida como de internação domiciliar. Promover a função do sujeito não passa apenas por considerar as medidas de socioeducação em função da transmissão dos conteúdos da cultura. É importante o momento em que o educador promova um espaço de reflexão sobre os conteúdos apresentados de forma o mais livre possível, ao tempo que siga um princípio ético de não permitir que isso acarrete danos morais aos jovens. Habitar esse limite nos parece ser uma importante tarefa na promoção da função do sujeito e uma importante questão a ser trabalhada neste projeto.

Esperamos, com nossa prática, que a Ética do desejo, transcendendo a qualquer moral pré-concebida, possibilite ao sujeito não ser esmagado pelas violentas forças presentes no contemporâneo que clamam por seu silenciamento. 


\section{REFERÊNCIAS}

BRASIL. (1988) Constituição da República Federativa do Brasil. Presidência da República. 5 de outubro de 1988. Brasília, DF.

BRASIL. (1990) Estatuto da Criança e do Adolescente, Câmara dos Deputados, Lei no 8.069, de 13 de julho de 1990. DOU de 16/07/1990 - ECA. Brasília, DF.

BRASIL. (2006) Sistema Nacional de Atendimento Socioeducativo - SINASE/ Secretaria Especial dos. Direitos Humanos. Brasília-DF: CONANDA.

BUTLER, J. (2004). Vida precária. El poder del duelo y la violência. Buenos Aires: Paidos.

HONNETH, A. (2003). Luta por reconhecimento: a gramática moral dos conflitos sociais. São Paulo: Ed. 34.

FACHIN, E. (2019) Ministro impõe medidas contra superlotação em mais quatro unidades de internação de adolescentes. In: http://www.stf.jus.br/portal/cms/verNoticiaDetalhe.asp?idConteudo=412292.

FREUD, S. (1976a). O mal-estar na civilização. In: Edição Standard Brasileira das Obras Psicológicas Completas de Sigmund Freud. V. XXI, pp. 75-173. Rio de Janeiro: Imago. Obra originalmente publicada em 1930 e escrita em 1929.

. (1976b). A questão da análise leiga. In: Edição Standard Brasileira das Obras Psicológicas Completas de Sigmund Freud. V. XX, pp. 205- 295. Rio de Janeiro: Imago. Obra originalmente publicada em 1926.

. (1976c). Psicologia de grupo e análise do ego. In: Edição Standard Brasileira das

Obras Psicológicas Completas de Sigmund Freud. V. XVIII, pp. 89-181. Rio de Janeiro: Imago. Obra originalmente publicada em 1921.

- (1976d). Romances familiares. In: Edição Standard Brasileira das Obras

Psicológicas Completas de Sigmund Freud. V. IX, pp. 241- 249. Rio de Janeiro: Imago. Obra originalmente publicada em 1909 e escrita em1908.

LACAN, J. (1982). O seminário, livro 7: A ética da psicanálise. Rio de Janeiro: Jorge Zahar. Seminários originalmente proferidos em 1959-1960.

(1985a). O seminário, livro 11: os quatro conceitos fundamentais da psicanálise.

Rio de Janeiro: Jorge Zahar, 2a. ed. Seminários originalmente proferidos em 1964. (1985b). O seminário, livro 20: mais ainda. Rio de Janeiro: Jorge Zahar.

Seminários originalmente proferidos em 1972 e 1973.

. (1998). A direção do tratamento e os princípios de seu poder. In: Escritos, pp. 591-

652. Rio de Janeiro: Jorge Zahar. Obra originalmente publicada em 1951. 
Psicologia, Psicanálise, Arte E Encarceramento Juvenil

STENGERS, I. (1990). Quem tem medo da ciência? Ciências e poderes. São Paulo: Siciliano.

WACQUANT, L. (2011). As prisões da miséria. $2^{\mathrm{a}}$ ed. Rio de Janeiro: Zahar. 


\title{
Psychology, Psychoanalysis, ARt And Youth \\ INCARCERATION
}

\begin{abstract}
The experience of early incarceration, often exacerbated by violence impetrated by State agents or by anonymous passers-by, is reported by countless adolescents, since the moment of their apprehensions, and extended to the interior of public institutions for socio-educational in Rio de Janeiro. The statistics of this macabre violence remain undervalued. In this wicked scenario, what psychology, psychoanalysis and art can do to help those young people to elaborate such powerful trauma, and to change such a cruel social status quo?
\end{abstract}

KEYWORDS: Socio-education, adolescence, violence, public institutions, psychoanalysis, art. 


\section{Psychologie, Psychanalyse, ARt Et Incarceration DE JEUNES}

\section{RÉSUMÉ}

L'expérience d'une incarcération précoce, souvent aggravée par la violence déclenchée par des passants anonymes ou par les agents de l'État, dès le moment de l'appréhension et étendue au sein d'institutions publiques, est rapportée par d'innombrables adolescents en conflit avec la loi arrêtés par décision judiciaire à Rio de Janeiro. Les statistiques de cette macabre violence restent sous-estimées. Dans ce pervers scénario, comment la psychologie, la psychanalyse et l'art peuvent-elles contribuer à l'élaboration subjective d'adolescents qui ont vécu des traumatismes aussi puissants, ainsi qu'à la transformation de ce cruel statu quo?

MoTS-ÉCLÉs: Socioéducation, adolescence, violence, institutions publiques, psychanalyse, art. 
(C) 2019 Psicanálise \& Barroco em revista

http://www.seer.unirio.br/index.php/psicanalise-barroco/index revista@psicanaliseebarroco.pro.br

Programa de Pós-Graduação em Memória Social — UNIRIO

Memória, Subjetividade e Criação

www.memoriasocial.pro.br/proposta-area.php 